Bulletin de la Société Royale des Sciences de Liège, Vol 85, 2016, p. 706 - 720

\title{
Developing a new PRW policy with limitation on each rectification cost
}

\author{
Mahdi NASROLLAHI, PhD \\ Assistant Professor of Industrial management Imam Khomeini International University \\ (IKIU), Qazvin, Iran \\ m.nasrollahi@soc.ikiu.ac.ir \\ Phone: +989125652670
}

\begin{abstract}
Warranty as a kind of service contract today plays a key role in business and legal transactions. Currently, a large number of products are being sold with warranty policies in the form of free replacement warranty, pro-rata warranty, and combined warranty policies. During PRW, when the product fails, the failed product is replaced with a new product with some cost to the consumer. Modeling failures and costs of PRW have complexities; because rectification cost of a product is in fact a random variable that interest rates and inflation will affect it. In this research we present a new pro rata warranty model. In this model the cost of individual claims to the manufacturer is limited to a predetermined fixed cost. Mathematical model for predicting expected costs to the manufacturer and buyer is developed at system level and analyzed by capturing the uncertainties of rectification costs over warranty period and considering the inflationary conditions. Finally, the model has been tested using numerical example.
\end{abstract}

Keywords: Warranty, warranty policies, Pro-rata warranty, warranty cost, Inflation.

\section{Introduction}

Increased competition has forced manufacturers to continuously add new features to their products this way they can maintain or increase their market share. Lower prices, better quality, and attractive warranties are examples of these features. Product warranty is a contract attached to the product at the time of the sale. It requires manufacturers/dealers to offer a pre-specified compensation to the buyers in the case of faulty product for a specified time period, providing that the product usage is according to its specification (Chukova and Shafiee, 2013). Product performances during the warranty period are defined by the interaction between product characteristics (defined by the manufacturer) and its usage (defined by the consumer). From the manufacturer point of view, the warranty is considered as a selling argument. From the consumer point of view, warranty insures the consumer that the defective entities will be repaired or replaced by the manufacturer during the warranty period at no cost or at a reduced cost depending on the terms of the warranty 
contract (Bouguerra, Chelbi and Rezg, 2012).

The concept of a warranty being an important strategic element has come to the forefront because of both promotional and protectional needs (Anderson, 1973). A warranty agreement usually includes the following specifications (Thomas and Rao, 1999):

1- $\quad$ The length of time during which the warranty is applicable,

2- the method of compensation for the product or service during the warranty period,

3- $\quad$ The condition for which the warranty agreement applies/ does not apply to the product or service,

4- The means by which the customer can claim the warranty.

The importance of warranty in determining customer preferences and product performance and manufacturer rights and duties is reflected in many researchers' works. If the seller promises to renew or repair products when failures occur, the commitment length of warranty and the reliability of the product, which is related to its failure time distribution, play a key role on deciding the total cost of the product.

A warranty policy is defined mainly by two elements: (1) the period of coverage, and (2) the terms of payment or compensation to the customer. Two types of warranty policies have been widely applied in practice: free replacement warranty policy (FRW) and pro-rata warranty policy (PRW). For a free replacement warranty policy, the seller is required to either repair the product or provide a new product at no cost to the buyer from the time of initial purchase. Such a policy is usually offered with repairable products. PRW policies are applied to items that are significantly influenced by aging. Pro-rata warranty policy requires the seller to provide replacement at some cost, which is called pro-rata cost, to the buyer.

Based on how long a producer should provide the warranty service, warranty policies can be classified into two types: fixed-period and renewable. In the fixed-period warranty, the warranted duration is specified at the time of product sale and remains fixed regardless of repairs or replacements of a warranted item. Most of the literature on warranty analysis deals with this type of warranty policy. In the renewable warranty, the warranty period is extended whenever repair or replacement has occurred during the warranty period. When the warranty period expires without any product failure, then the warranty terms expire completely. Successive failure times in the renewable warranty form a renewal process, and renewal theory can be adopted to describe this process (Chun and Tang, 1995).

According to the aforementioned taxonomy, the warranty policy we consider in this paper can be described as a Pro-rata, fixed-period warranty policy, which is one of the most common types of warranty policies in practice. Under this warranty policy, if customers pay the warranty price at the time of product purchase, the producer provides as many 
repairs or replacements as necessary at some cost for any failures occurring during the warranty period. The original warranty period is not extended after repairs or replacements.

\section{Literature review}

Depending upon the type of product, an appropriate warranty policy needs to be selected. A lot of research has been carried on for selection of an appropriate warranty policy and warranty length by considering either the manufacturer's or the buyer's point of view. Offering an attractive warranty policy is typically costly.

Blischke and Murthy (1992) have proposed taxonomy for warranty policies for new products and grouped these policies into number of categories. Murthy and Chattopadhyay (1999) have developed policies and taxonomy for second hand products. Murthy and Blischke (2006) have discussed in detail about the warranty polices and the associated warranty cost analysis.

In the literature, the optimization of warranty is carried out in which objective functions for optimization are the minimization of the expected warranty cost and price, maximization of the expected profit per product and market share, improvement of reliability ( Mitra and Patankar, 1988; Yun, 1997; Liu et al., 2006; Lu and Chiang, 2008; Wu et al., 2009; Saidi-Mehrabad et al., 2010; Shafiee et al., 2011; Shafiee and Zuo, 2011; Park and Pham, 2012; Faridimehr and Niaki, 2012).

Determining the optimal pro rata warranty price has been the subject of many studies. In Table 1 we present a summary and brief overview of the publications within the last 10 years (2005-2015). 
Bulletin de la Société Royale des Sciences de Liège, Vol 85, 2016, p. 706 - 720

Table 1: A literature review on determining the optimal warranty cost (since 2005)

\begin{tabular}{|c|c|c|}
\hline Author/s & Year & Abstract \\
\hline $\begin{array}{l}\text { Park, } \\
\text { Jung, and } \\
\text { Park }\end{array}$ & 2014 & $\begin{array}{l}\text { New warranty cost models are developed and the } \\
\text { renewable warranty policy is investigated for free and pro- } \\
\text { rata two-dimensional warranty dependent on both failure } \\
\text { time and warranty servicing time. }\end{array}$ \\
\hline $\begin{array}{l}\text { Yeh and } \\
\text { Fang }\end{array}$ & 2014 & $\begin{array}{l}\text { Proposes a Bayesian decision-making model which } \\
\text { considers the PRW policy with the pricing and the } \\
\text { production strategy. }\end{array}$ \\
\hline $\begin{array}{l}\text { Ambad } \\
\text { and } \\
\text { Kulkarni }\end{array}$ & 2013 & $\begin{array}{l}\text { developed a conceptual framework that integrates the } \\
\text { technology and commercial issues early at the design } \\
\text { stage to minimize warranty costs in the most } \\
\text { effective and efficient manner }\end{array}$ \\
\hline $\begin{array}{l}\text { Popovic, } \\
\text { Stamenko } \\
\text { vic, and } \\
\text { Rakicevic }\end{array}$ & 2012 & $\begin{array}{l}\text { Deals with the warranty cost analysis for one type of } \\
\text { passenger car batteries. Obtained results are guideline for } \\
\text { the manufacturer to choose the warranty that minimizes } \\
\text { the costs and maximizes the profit. }\end{array}$ \\
\hline $\begin{array}{c}\text { Park and } \\
\text { Pham }\end{array}$ & 2012 & $\begin{array}{l}\text { Develop a new warranty policy with respect to the failure } \\
\text { time and warranty servicing time, where those two } \\
\text { variables are statistically correlated in bivariate } \\
\text { distributions. }\end{array}$ \\
\hline Chien & 2010 & $\begin{array}{l}\text { This paper focuses on an age-replacement policy for } \\
\text { products under a new warranty strategy, which combines a } \\
\text { fully renewable free replacement with a pro-rata warranty } \\
\text { policy }\end{array}$ \\
\hline $\begin{array}{c}\text { Fang and } \\
\text { Huang }\end{array}$ & 2010 & $\begin{array}{l}\text { Proposes a Bayesian decision model by which the } \\
\text { integrated optimal strategy can be obtained under the } \\
\text { situation that the manufacturer does not have sufficient } \\
\text { historical data. }\end{array}$ \\
\hline Chien & 2008 & $\begin{array}{l}\text { A new warranty policy is proposed and analyzed for } \\
\text { repairable products. This policy combines a renewing } \\
\text { free-replacement warranty with a rebate policy }\end{array}$ \\
\hline $\begin{array}{l}\text { Jain and } \\
\text { Maheshw } \\
\quad \text { ari }\end{array}$ & 2006 & $\begin{array}{l}\text { Proposed a hybrid warranty model for the renewing pro- } \\
\text { rata warranty (RPRW), in which the failure rate of units } \\
\text { cost of preventive maintenance and cost of replacement } \\
\text { are assumed to be constant. }\end{array}$ \\
\hline $\begin{array}{l}\text { Chukova } \\
\text { and } \\
\text { Hayakaw }\end{array}$ & 2005 & $\begin{array}{l}\text { It is observed that quasi-renewal and the geometric } \\
\text { processes are equivalent. The corresponding expected } \\
\text { warranty cost over the warranty period under a non- }\end{array}$ \\
\hline
\end{tabular}


\begin{tabular}{|c|l|l|}
\hline a & renewing warranty policy is evaluated. \\
As can be seen from the above review, minimization of warranty cost is a
\end{tabular} multidimensional problem. In addition to this, the complexity of the problem is very high due to the way in which many parameters affect warranty cost. This brief review of the existing cost optimization models in pro rata warranty shows that they focus on minimizing a cost function that incorporates warranty cost for whole product and do not group components into disjointed sets.

So in this study, a Pro-rata warranty model was developed to predict failures and estimating costs. The proposed model is suitable for products that some parts were covered under warranty and some others are not covered under warranty. So the manufacturer in estimating the warranty costs should consider these two components separately. In this regard, after a brief literature review, the role of inflation and deflation on the cost of the warranty will be discussed. And then, the mathematical model for the PRW Policy presented and the validity of the model is evaluated by a numerical example.

\section{Assumption and Notations}

A product can be treated as a system comprising number of components and failures can be modeled at the system or sub-system level. Here we assume cumulative failure distribution of the product is modeled as $F(x)$ with density function $f(x)=\frac{d F(x)}{d x}$ and the product failure intensity function is modeled as (Rahman \& Chattopadhyay, 2010):

$$
\Lambda(\mathrm{x})=\frac{\mathrm{f}(\mathrm{x})}{(1-\mathrm{F}(\mathrm{x}))}
$$

\subsection{Assumptions}

- Item failures are statistically independent.

- Item failure is only a function of its age.

- The time to carry out a rectification action by replacement is negligible compared to the mean time between failures and this time is ignored.

- An item failure results in an immediate claim and all claims are valid.

- All defective parts will be replaced with new parts.

- Failures during the warranty period are modeled at the system level.

\subsection{Notations}

We use the following notations for the purpose of this paper. Subscripts $m$ and $c$ stands for manufacturer and costumer respectively. 
$f \quad$ increasing rate of cost due to inflation;

$d \quad$ Discount rate (annuity);

I $\quad f-d$ present value of the nominal inflation rate;

$\beta \quad$ shape parameter of product failure distribution;

$\lambda \quad$ inverse characteristic life parameter;

$\Lambda(x)$ intensity function for product failure;

$W \quad$ warranty coverage period;

$\bar{C} \quad$ Expected cost of each rectification over the warranty period (system level);

$x \quad$ Product failure time;

$q(x)$ rebate function;

$F($.) Cumulative distribution function of product failure;

$f($.$) \quad Failure density function;$

$G($.$) Cumulative distribution function for product rectification cost;$

$g($.$) \quad Probability density function for product rectification cost;$

$N(0, W) \quad$ number of failures over the warranty period

$M_{j} \quad$ manufacturer's costs for the $J^{\text {th }}$ failure under warranty;

$B_{j} \quad$ customer's costs for the $J^{\text {th }}$ failure under warranty;

$c_{b} \quad$ The cost of rectification (repair cost) for a customer in each occasion of failure if the item is not warranted. When all rectifications are carried out by the manufacturer for some technical reasons, the policy is called manufacturer's technical monopoly. This paper assumes there is no manufacturer's technical monopoly;

$c_{m} \quad$ the manufacture's per occasion cost of rectification (repair cost) when the item is covered under warranty;

$C_{W} \quad$ The warranty price offered by the manufacturer during the time of purchase.

\section{PRW mathematical model: Limit on Individual Cost Pro Rata Warranty (LICPRW)}

The cost of each repair $C$ is, in general, a random variable because an item failure is due to the failure of one or more of its components and cost of repair or replacement varies with components. We assume $G(c)$ and $g(c)$ as the cumulative distribution function and density function of rectification costs of the product over the warranty period i.e.

$$
G(c)=P\{R \leq c\}
$$

Then the expected cost of each rectification action, $\mathrm{E}(\mathrm{c})=\overline{\mathrm{c}}$, is given by

$$
E(c)=\bar{c}=\int_{0}^{\infty} \operatorname{cg}(c) d c
$$

For products with longer warranty periods, such as cars, the total warranty cost is uncertain over a longer period of time due to uncertainties of costs of servicing claims. If the 
warranty period is very long (usually more than one year), the future costs will be affected by increased labor costs, inflation and devaluation of money over time (Chattopadhyay \& Rahman; 2007).

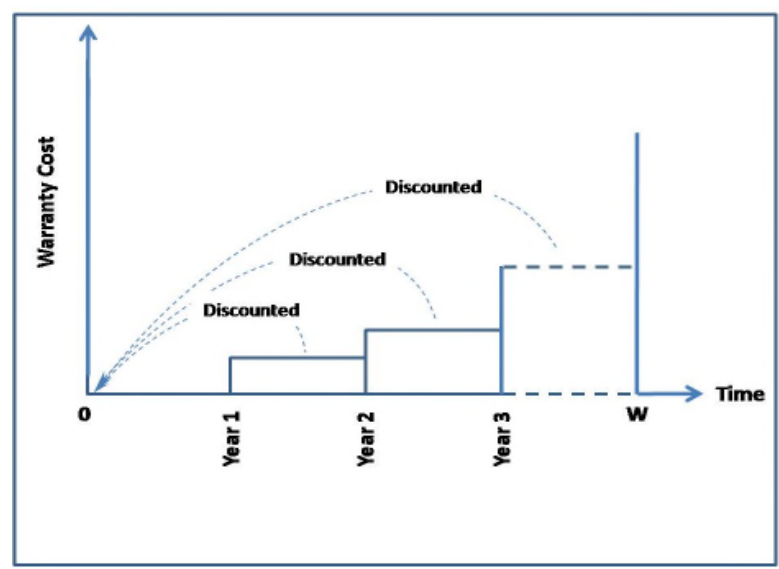

Figure 1: Effects of discounting for warranty costs under longer warranty period

For inflation rate $f$, the continuous time inflation factor for the time period $W$ is $e^{f W}$ which means that an item that costs $C$ dollars at time $W=0$ will cost $C e^{f W}$ at time $t$. For a discount rate, $d$, representing the time value of money, the present value factor of an amount at time $W$, is $e^{-d W}$. Hence, the present value of the inflated amount $C e^{f W}$ (net inflation factor) is $C e^{f W} e^{-d W}$. For an item with initial price $C$ (\$/unit), the present value of the inflated price of an item at time $W=0, C_{0}$ is given by (Sarker et al., 2000).

$$
C_{0}=C e^{(f-d) W}=C e^{I W}, I=f-d
$$

in which $C$ is inflated through time $W$ to $e^{f W}, e^{-d W}$ is the factor deflating the future worth to its present value, and $I$ is the present value of the inflation rate (Sarker et al., 2000; Giri \& Bardhan, 2011; Pandey \& Gupta, 2011).

Let the expected number of failures and the expected cost of warranty claims for year i be $E(N i)$ and $E(C i)$, respectively. Costs of premiums are assumed to occur at the beginning of every year (Chattopadhyay \& Rahman; 2007). Then the present value of the expected cost for warranty period can be modeled as

$$
E(C)=\sum_{i=1}^{W} E\left(N_{i}\right) E\left(C_{i}\right) e^{i i}
$$

Based on PRW policy, this cost will be divided between manufacturer and customer. 
In proposed model the cost of individual claims of costumer is limited to a predetermined fixed cost $C_{I}$. Thus the manufacturer carries out all rectification action at a prorated cost to the costumer if the cost of rectification is below a limit $C_{I}$. If the cost of rectification exceeds $C_{I}$, then the costumer in addition to him/her share of cost should pay the difference between the manufacturer cost of rectification and $C_{I}$. That is the manufacturer pays all costs up to $C_{I}$ and the costumer in addition to him/her cost pays an amount $\left(C_{J^{-}} C_{I}\right)$; where $C_{J}$ is the total rectification costs of an individual claim.

The manufacturer cost share from total rectification cost under PRW policy is given by:

$$
\mathrm{C}_{\mathrm{m}}=\mathrm{C}_{\mathrm{J}}(1-\mathrm{x} / \mathrm{W})
$$

Thus the costumer should at least pay $\left(C_{J}-C_{m}\right)$. Now based on this model, the final cost imposed to the manufacturer and the costumer for the $j^{\text {th }}$ failure is given by:

$$
\begin{aligned}
& M_{J}=\min \left\{C_{I}, C_{m}\right\} \\
& B_{J}=\left(C_{J}-C_{m}\right)+\max \left\{0,\left(C_{m}-C_{I}\right)\right\}
\end{aligned}
$$

Where $M_{J}$ and $B_{J}$ represent the manufacturer's cost and costumer's costs for $j^{\text {th }}$ failure respectively.

If the individual cost of rectification, $C_{J}$ be given by a distribution function $G(c)$ with density function $g(c)$, therefore the expected cost of each rectification to the manufacturer is given by

$$
\overline{C_{m}}=\int_{0}^{c_{l}} \mathrm{C}(1-\mathrm{x} / \mathrm{W}) g(C) d(C)+C_{l} \bar{G}\left(C_{l}\right)
$$

Where $\bar{G}\left(C_{I}\right)=\int_{C_{I}}^{\infty} g(C) d(C)$; and this cost to the costumer is given by

$$
\overline{c_{b}}=c^{x} / W+\int_{c_{l}}^{\infty}\left(\mathrm{C}-\mathrm{C}_{1}\right) g(c) d(C)
$$

The expected number of failure is given by 


$$
E[N(0, W)]=\int_{0}^{W} \Lambda(x) d x
$$

The total expected warranty cost to the manufacturer is given by

$$
E\left[C_{m}\left(0, W^{\prime}\right)\right]=e^{I W} \bar{C}_{m}\left[\int_{0}^{W} \Lambda(x) d x\right]
$$

And the total expected cost to the costumer over the warranty period is given by

$$
E\left[C_{b}(0, W)\right]=e^{I W} \overline{C_{b}}\left[\int_{0}^{W} \Lambda(x) d x\right]
$$

We assume failure of the product follow the non-homogeneous Poisson process with inverse characteristic life parameters $\lambda$ and shape parameter $\beta$. therefore the total expected warranty cost to the manufacturer over the warranty period is given by

$$
E\left[C_{m}(0, W)\right]=e^{I W} \bar{c}_{m}\left[\int_{0}^{W} \lambda \beta(\lambda x)^{(\beta-1)} d x\right]
$$

And the total expected cost to the costumer over the warranty period is given by

$$
E\left[C_{b}(0, W)\right]=e^{I W} \bar{c}_{b}\left[\int_{0}^{W} \lambda \beta(\lambda x)^{(\beta-1)} d x\right]
$$

\section{Numerical example}

In this subsection, the sensitivity of optimal warranty cost is analyzed with the variation of Length of warranty period, failure parameters, and discount and inflation rate, respectively.

Let $\beta=2$ and $\lambda=0.443$ per year, and let $C_{I}=\mathbf{1 5}$. This implies that if the cost of a rectification on each occasion is below the limit $C_{I}$, then it is borne completely by the PRW policy between manufacturer/dealer and the customer. If the cost of a rectification exceeds $C_{I}$, the buyer pays all the costs in excess of $C_{I}$.

\subsection{Effect of Length of warranty period on the warranty cost}

The expected warranty costs, $E[C(0, W)]$ for different periods for manufacturer and costumer are shown in Table 2. 
Bulletin de la Société Royale des Sciences de Liège, Vol 85, 2016, p. 706 - 720

Table 2: Warranty cost (\$) to the manufacturer and costumer for different warranty periods

\begin{tabular}{|c|c|c|c|c|c|}
\hline $\mathrm{W}$ & 2 & 2.5 & 3 & 3.5 & 4 \\
\hline$E\left[C_{m}(0, W)\right]$ & 10.08 & 16.45 & 24.80 & 35.40 & 48.58 \\
\hline$E\left[C_{b}(0, W)\right]$ & 17.97 & 30.25 & 46.47 & 67.00 & 92.23 \\
\hline
\end{tabular}

The figure 2 shows that with the given failure distribution the warranty cost increases as the warranty period increases this implies the longer warranty period the more the number of failures and higher the cost to the manufacturer and costumer.

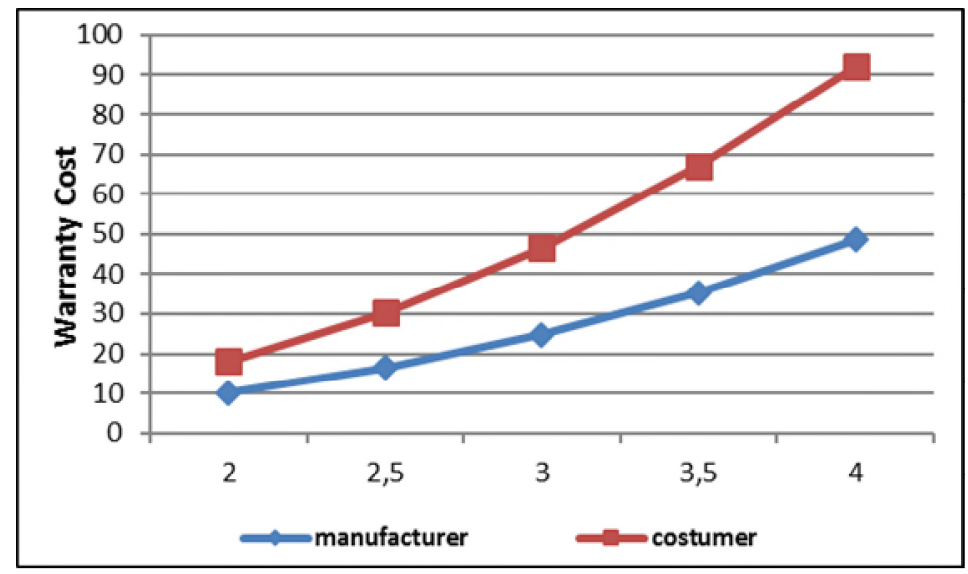

Figure 2: Expected warranty cost to the manufacturer and costumer for different warranty periods

\subsection{Effect of failure parameters on the warranty cost}

Here, the sensitivity of product failure rate or intensity of product failure on the warranty cost is analyzed. To examine the influence of product failure rate on the warranty cost, $\beta$ is varied from 1 to 3 and $\lambda$ is varied from 0.20 to 0.40 per year keeping all other parameters as above. The computer simulation program generates the Tab. 3 for the warranty costs with variation of the failure parameters $(W=3)$. 
Bulletin de la Société Royale des Sciences de Liège, Vol 85, 2016, p. 706 - 720

Table 3: Warranty cost $(\$)$ to the manufacturer for different failure parameters $(\mathrm{W}=3)$

\begin{tabular}{|c|c|c|c|c|c|c|}
\hline \multicolumn{2}{|c|}{} & \multicolumn{5}{|c|}{$\lambda$} \\
\cline { 2 - 7 } \multicolumn{2}{c|}{} & 0.200 & 0.250 & 0.300 & 0.350 & 0.400 \\
\hline \multirow{4}{*}{$\beta$} & 1.0 & 7.59 & 9.15 & 10.71 & 12.27 & 13.83 \\
\cline { 2 - 7 } & 1.5 & 6.18 & 8.11 & 10.23 & 12.54 & 15.02 \\
\cline { 2 - 7 } & 2.0 & 5.09 & 7.20 & 9.77 & 12.82 & 16.33 \\
\cline { 2 - 7 } & 2.5 & 4.25 & 6.42 & 9.34 & 13.10 & 17.76 \\
\cline { 2 - 7 } & 3.0 & 3.60 & 5.74 & 8.93 & 13.39 & 19.32 \\
\hline
\end{tabular}

Table 3 shows that the manufacturer's warranty cost increases as the inverse characteristic life parameter $(\lambda)$ increases and this cost decreases as the shape parameter $(\beta)$ increases (Figure 3).

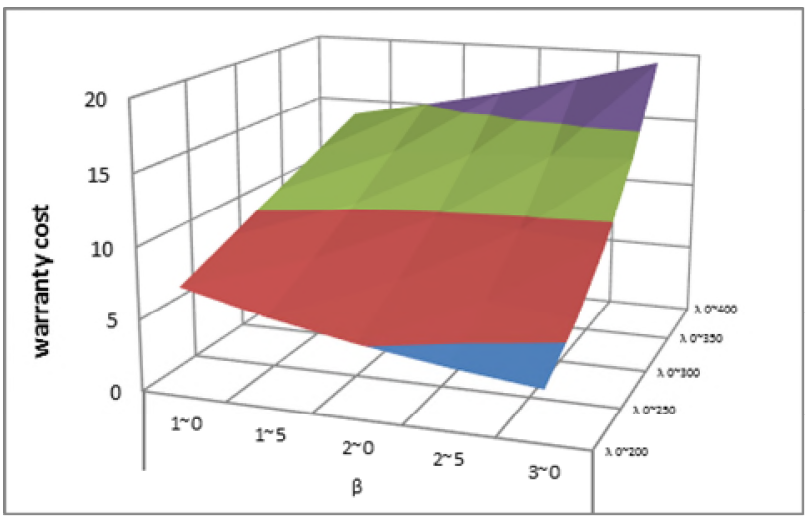

Figure 3: Expected warranty cost to the manufacturer and costumer for different failure parameters

\subsection{Effect of discount and inflation rate on the warranty cost}

An analysis if sensitivity of discount and inflation rate on the warranty cost is made here. To see the influence of discount and inflation rate on warranty cost the $d$ is varied from 0.03 to 0.27 and the $f$ is varied from 0.1 to 0.3 respectively in the table $4(W=3)$. 
Bulletin de la Société Royale des Sciences de Liège, Vol 85, 2016, p. 706 - 720

Table 4: Warranty cost $(\$)$ to the manufacturer for different discount and inflation rate $(\mathrm{W}=3)$

\begin{tabular}{|c|c|c|c|c|c|c|}
\hline \multicolumn{2}{|c|}{} & \multicolumn{5}{|c|}{$d$} \\
\cline { 2 - 7 } \multicolumn{2}{|c|}{} & 0.030 & 0.090 & 0.150 & 0.210 & 0.270 \\
\hline \multirow{4}{*}{$f$} & 0.10 & 7.59 & 9.15 & 10.71 & 12.27 & 13.83 \\
\cline { 2 - 7 }$f$ & 0.15 & 6.18 & 8.11 & 10.23 & 12.54 & 15.02 \\
\cline { 2 - 7 } & 0.20 & 5.09 & 7.20 & 9.77 & 12.82 & 16.33 \\
\cline { 2 - 7 } & 0.25 & 4.25 & 6.42 & 9.34 & 13.10 & 17.76 \\
\cline { 2 - 7 } & 0.30 & 3.60 & 5.74 & 8.93 & 13.39 & 19.32 \\
\hline
\end{tabular}

This table shows that the warranty cost increases as the inflation rate increases. Conversely when the discount rate increases the warranty cost will decrease.

\section{Conclusion and Future works}

The main contributions of this paper are: (i) considering rectification cost present value in estimating expected warranty cost for manufacturer and customer; (ii) considering the rectification cost as a random variable and using a probability function for estimating the cost of each failure; (iii) considering the two parameter Weibull distribution failure rate function for estimating the total expected cost; and (iv) limitation on individual cost PRW policy. In proposed model the cost of individual claims to the manufacturer is limited to a predetermined fixed cost. Thus the manufacturer carries out all rectification action at a prorated cost to the costumer if the cost of rectification is below a limit $C_{I}$. This policy can be used for products with high rate of expected failure during the warranty period. It is also possible that periodic preventive maintenance policy added to warranty contract terms. So this model can be useful for manufacturers when making decisions about warranty pricing.

Future works could be performed on refining the proposed model by considering the impact of preventive maintenance and periodic replacement during the warranty period on the product failure rate and future costs. It would also be worth investigating whether a two-dimensional warranty concerning both time and usage for deteriorating products. This model was developed at a system level. One can develop cost models at a component level by applying renewal, modified renewal or other relevant processes and aggregating to the system level. And finally, in estimating warranty cost, it was assumed that an item failure result in an immediate claim and all claims are valid. In practice, there are a number of instances when a warranty is not exercised, even though it is possible to do so. The percentage of customers who actually use their warranties is uncertain. Relaxation of this assumption can make the model more realistic. 
Bulletin de la Société Royale des Sciences de Liège, Vol 85, 2016, p. 706 - 720

\section{References}

1. Ambad, P.M., \& Kulkarni, M.S. (2013). "A methodology for design for warranty with focus on reliability and warranty policies". Journal of Advances in Management Research, 10(1), 139-155.

2. Blischke, W.R. \& Murthy, D.N.P. (1992). "Product warranty management - I: a taxonomy for warranty policies". European Journal of Operational Research, 62(2), 127-148.

3. Bouguerra, S., Chelbi A. \& Rezg, N. (2012). "A decision model for adopting an extended warranty under different maintenance policies". International Journal of Production Economics, 135, 840-849.

4. Chattopadhyay, G. \& Rahman, A. (2008). "Development of lifetime warranty policies and models for estimating costs". Reliability Engineering and System Safety, 93(4), 522-529.

5. Chien, Y.H. (2008). "A new warranty strategy: Combining a renewing freereplacement warranty with a rebate policy". Quality and Reliability Engineering International, 27(7), 807-815.

6. Chien, Y.H. (2010), "Optimal age for preventive replacement under a combined fully renewable free replacement with a pro-rata warranty". International Journal of Production Economics, 124, 198-205.

7. Chukova, S. \& Hayakawa, Y. (2005). "Warranty cost analysis: quasi-renewal inter-repair times". International Journal of Quality \& Reliability Management, 22(7), 687 - 698 .

8. Chukova, H. \& Shafiee, M. (2013), "One-dimensional warranty cost analysis for second-hand items: an overview". International Journal of Quality \& Reliability Management, 30(3), 239-255.

9. Chun, Y.H. \& Tang, K. (1995). "Determining the optimal warranty price based on the producer's and customers' risk preferences". European Journal of Operational Research, 85, 97-110.

10. Fang, C.C. \& Huang, Y.S. (2010). "A study on decisions of warranty, pricing, and production with insufficient information". Computers \& Industrial Engineering, 59, 241-250.

11. Faridimehr, S. \& Niaki, S.T.A. (2012). "A note on optimal price, warranty length and production rate for free replacement policy in static demand markets". Omega, 40(6), 805-806.

12. Giri, B.C. \& Bardhan, S. (2011). "Coordinating a two-echelon supply chain under inflation and time value of money". International Journal of Industrial Engineering Computations, 2, 811-818. 
Bulletin de la Société Royale des Sciences de Liège, Vol 85, 2016, p. 706 - 720

13. Jain, M. \& Maheshwari, S. (2006). "Discounted costs for repairable units under hybrid warranty". Applied Mathematics and Computation, 173, 887901.

14. Liu, Z.J., Huang, H.Z. \& Murthy, D.N.P. (2006). "Optimal reliability and price choices for products under warranty". Proceedings of Annual Reliability and Maintainability Symposium, Newport Beach, CA. 146-151.

15. Lu, L.Y.Y. \& Chiang, C.C. (2008). "Prediction model for warranty costs: a case study of a LCD monitor company". 2008 IEEE Asia-Pacific Services Computing Conference, Yilan, 1418-1423.

16. Mitra, A. \& Patankar, J.G. (1988). "Warranty cost estimation: a goal programming approach". Decision Science, 19(2), 409-423.

17. Murthy, D.N.P. \& Blischke, W.R. (2006). "Warranty Management and Product Manufacturer". Springer-Verlag London Ltd, London.

18. Murthy, D.N.P. \& Chattopadhyay, G.N. (1999). "Warranties for second-hand products". $9^{\text {th }}$ International Conference of Flexible Automation and Intelligent Manufacturing (FAIM), Tilburg, 1145-1159.

19. Pandey, R.K. \& Gupta, S. (2011). "Supply Chain Inventory Model with Time Dependent Demand for Decaying Items under Inflation". International Transactions in Applied Sciences 3(1), 122-130.

20. Park, M., Jung, K.M., \& Park, D.H. (2014). "Optimal warranty policies considering repair service and replacement service under the manufacturer's perspective". Annals of Operations Research DOI 10.1007/s10479-014-17401 .

21. Park, M. \& Pham, H. (2012). "A New Warranty Policy with Failure Times and Warranty Servicing Times". IEEE Transactions on Reliability, 61(3), 822-831.

22. Park, M. \& Pham, H. (2012). "Warranty cost analysis for k-out-of-n systems with 2-D warranty". IEEE Transactions on Systems, Man, and Cybernetics Part A: Systems and Humans, 42(4), 947-957.

23. Rahman, A \& Chattopadhyay, G. (2010). "Modeling risks to manufacturer and buyer for lifetime warranty policies". International Journal of Management Science and Engineering Management, 5(3), 203-209.

24. Saidi-Mehrabad, M., Noorossana, R., \& Shafiee, M. (2010). "Modeling and analysis of effective ways for improving the reliability of secondhand products sold with warranty". The International Journal of Advanced Manufacturing Technology, 46(1-4), 253-265.

25. Sarker, B.R., Jamal, A.M.M. \& Wang, S. (2000). "Supply chain models for perishable products under inflation and permissible delay in payment". Computers \& Operations Research, 27, 59-75. 
Bulletin de la Société Royale des Sciences de Liège, Vol 85, 2016, p. 706 - 720

26. Shafiee, M. \& Zuo, M.J. (2011). "Optimizing burn-in procedure and warranty policy in lifecycle costing". 2011 International Conference on Quality, Reliability, Risk, Maintenance, and Safety Engineering (ICQR2MSE), Xi'an, 540-544.

27. Shafiee, M., Chukova, S., Yun, W.Y. \& Niaki, S.T.A. (2011). "On the investment in a reliability improvement program for warranted second-hand items". IIE Transactions, 43(7), 525-534.

28. Thomas, M.U. \& Rao, S.S. (1999). "Warranty economic decision models: A summary and some suggested directions for future research". Operations research, 47(6), 807-820.

29. Wu, C.C., Chou, C.Y. \& Huang, C. (2009). "Optimal price, warranty length and production rate for free replacement policy in the static demand market". Omega, 37(1), 29-39.

30. Yeh, C.W. \& Fang, C.C. (2014). "Optimal pro-rata warranty decision with consideration of the marketing strategy under insufficient historical reliability data". International Journal of Advanced Manufacturing and Technology, 71, 1757-1772.

31. Yun, W.Y. (1997). "Expected value and variance of warranty cost of repairable product with two types of warranty". International Journal of Quality and Reliability Management, 14(7), 661-668. 